\title{
The role of ethylene in rhizobacteria-induced systemic resistance (ISR)
}

Pieterse, C.M.J.*, Van der Ent, S., Van Pelt, J.A. and Van Loon, L.C.

Section Phytopathology, Institute of Environmental Biology, Faculty of Science, Utrecht University, P.O. Box 800.84, 3508 TB Utrecht, The Netherlands. Phone +31 30253 6887; Fax +31 302518366 .

(*Corresponding author: C.M.J.Pieterse@bio.uu.nl)

\section{Introduction}

To protect themselves from disease, plants have evolved sophisticated defense mechanisms in which the signal molecules salicylic acid (SA), jasmonic acid (JA) and ethylene (ET) often play crucial role (Pieterse and Van Loon, 1999). Elucidation of signaling pathways controlling disease resistance is a major objective in research on plant-pathogen interactions. The capacity of a plant to develop a broad-spectrum, systemic acquired resistance (SAR) after primary infection with a necrotizing pathogen is well known and its signal transduction pathway extensively studied (Durrant and Dong, 2004). Plants of which the roots have been colonized by specific strains of nonpathogenic fluorescent Pseudomonas spp. develop a phenotypically similar form of protection that is called rhizobacteria-mediated induced systemic resistance (ISR) (Van Loon et al., 1998). In contrast to pathogen-induced SAR, which is regulated by SA, rhizobacteria-mediated ISR is controlled by a signaling pathway in which ET and JA play key roles (Pieterse et al., 1998). In the past decade, the model plant species Arabidopsis thaliana was explored to study the molecular basis of rhizobacteria-mediated ISR (Pieterse et al., 2002). Here we review the current knowledge of the signal transduction steps involved in the ISR pathway that leads from recognition of the rhizobacteria in the roots to systemic expression of broad-spectrum disease resistance in above-ground foliar tissues. 


\section{Rhizobacteria-Induced Systemic Resistance (ISR)}

To study the signal transduction pathway of ISR, an Arabidopsis-based model system was developed. In this model system, the nonpathogenic rhizobacterial strain Pseudomonas fluorescens WCS417r is used as the inducing agent (Pieterse et al., 1996). Colonization of Arabidopsis roots by ISR-inducing WCS417 $\mathrm{r}$ bacteria protects the plants against different types of pathogens, including the bacterial pathogens Pseudomonas syringae pv. tomato (Pst) DC3000, Xanthomonas campestris pv. armoraciae, and Erwinia carotovora pv. carotovora, the fungal root pathogen Fusarium oxysporum f.sp. raphani, the fungal leaf pathogens Alternaria brassicicola and Botrytis cinerea, and the oomycete pathogen Hyaloperonospora parasitica (Pieterse et al., 1996; Ton et al., 2002a).

Research on the molecular mechanism of ISR was initially focused on the role of pathogenesis-related (PR)-proteins, as the accumulation of these proteins was considered to be strictly correlated with induced disease resistance (Van Loon et al., 2006). However, Arabidopsis plants expressing WCS417rmediated ISR showed enhanced resistance against $F$. oxysporum and Pst DC3000, but this did not coincide with the activation of the SAR marker genes $P R-1, P R-2$, and PR-5 (Pieterse et al., 1996). Determination of SA levels in ISR-expressing Arabidopsis plants revealed that ISR is not associated with increased accumulation of SA (Pieterse et al., 2000). Moreover, WCS417r-mediated ISR was expressed normally in SA-nonaccumulating Arabidopsis NahG plants (Pieterse et al., 1996), and in the SA biosynthesis mutants eds5/sidl and sid2 (Pieterse et al., 2002). This led to the conclusion that WCS417r-mediated ISR is a SA-independent resistance mechanism, and that WCS417r-mediated ISR and pathogen-induced SAR are regulated by distinct signaling pathways.

\section{Genetic Dissection of the ISR Pathway in Arabidopsis}

Since SA was not involved in WCS417r-elicited ISR, the Arabidopsis JAresponse mutants jarl, coil, and eds8, and the ET-response mutant etrl were tested for their ability to express ISR. None of these mutants were unable to mount resistance against Pst DC3000 after colonization of the roots by WCS417r (Pieterse et al., 1998; Ton et al., 2002b; unpublished data), indicating that ISR requires responsiveness to both JA and ET (Fig. 1). To further elucidate the role of ET in the ISR signaling pathway, a large set of well-characterized ET-signaling mutants was analyzed. None of these mutants showed an ISR response against Pst DC3000 after colonization of the roots by WCS417r (Knoester et al., 1999). These results confirmed that 
an intact ET-signaling pathway is required for the establishment of ISR. Particularly interesting was the analysis of the eirl mutant, which is ETinsensitive in the roots, but not in the shoot. This eirl mutant was incapable of showing ISR after root colonization by WCS417r. In contrast, after leaf infiltration with WCS417r it did show ISR, indicating that responsiveness to ET is required at the site of rhizobacterial induction (Knoester et al., 1999). The observation that the ET-responsive Arabidopsis AtTLPl gene, encoding a thaumatin-like protein, is activated in the roots upon colonization by WCS417r, confirms that ET signaling is initiated in the roots by ISRinducing rhizobacteria (Léon-Kloosterziel et al., 2005).

Further evidence for the involvement of the ET-response pathway came from the identification of the Arabidopsis ISRI locus (Ton et al., 1999). Genetic analysis of the progeny of a cross between the WCS417r-responsive ecotype Col- 0 and the ISR-impaired ecotype RLD1 revealed a single locus, designated $I S R I$, to be important in the expression of ISR against several different pathogens (Ton et al., 2002c). Accessions with the recessive isrl allele have reduced sensitivity to ET and enhanced susceptibility to Pst DC3000 (Ton et al., 2001). These results strongly indicate that the Arabidopsis ISRI locus encodes a novel component in the ET-signal transduction pathway that is important for both basal resistance and ISR in Arabidopsis.

\section{Dual Role for NPR1 in SAR and ISR}

To investigate a possible involvement of the SAR regulatory protein NPR1 in ISR signaling, the Arabidopsis npr1 mutant was tested in the ISR bioassay. Surprisingly, the nprl mutant was incapable of showing WCS417rmediated ISR (Pieterse et al., 1998; Van Wees et al., 2000) (Fig. 1). This result clearly showed that WCS417r-mediated ISR, like SA-dependent SAR, is an NPR1-dependent defense response. Further analysis of the ISR signal-transduction pathway revealed that NPR1 acts downstream of the JA- and ET-dependent steps (Pieterse et al., 1998). Because SAR is associated with NPR1-dependent $P R$-gene expression, and ISR is not, the action of NPR 1 in ISR must be different from that in SAR. These different activities are not mutually exclusive because simultaneous activation of ISR and SAR can lead to an enhanced defensive activity compared to that observed with either type of induced resistance alone (Van Wees et al., 2000). These results suggest that the NPR1 protein is important in regulating and intertwining different hormone-dependent defense pathways. 


\section{ISR Is Associated with Priming for Enhanced Defense}

In Arabidopsis, both JA and ET activate specific sets of defense-related genes (Schenk et al., 2000) but, when applied exogenously, each of both can induce resistance (Pieterse et al., 1998; Van Wees et al., 1999). To investigate how far ISR is associated with these changes in JA/ET-responsive gene expression, Van Wees et al. (1999) monitored the expression of a set of well-characterized JA- and/or ET-responsive, defense-related genes in Arabidopsis plants expressing WCS417r-mediated ISR. None of these genes was up-regulated in induced plants, neither locally in the roots, nor systemically in the leaves. This suggested that the resistance attained was not associated with major increases in the levels of either JA or ET. Indeed, analysis of JA and ET levels in leaves of ISR-expressing plants revealed no changes in the production of these signal molecules (Pieterse et al., 2000; Hase et al., 2003). Therefore, it had to be assumed that the JA and ET dependency of ISR is based on an enhanced sensitivity to these hormones, rather than on an increase in their production.

To identify ISR-related genes, the transcriptional response of over 8000 Arabidopsis genes was monitored during WCS417r-mediated ISR (Verhagen et al., 2004). However, systemically in the leaves, none of the $\sim 8000$ genes tested showed a consistent change in expression in response to effective colonization of the roots by WCS417r, indicating that the onset of ISR in the leaves is not associated with detectable changes in gene expression. However, after challenge inoculation of WCS417r-induced plants with Pst DC3000, 81 genes showed an augmented expression pattern in ISRexpressing leaves compared to inoculated control leaves, suggesting that ISR-expressing plants are primed to respond faster and/or more strongly upon pathogen attack. The majority of the primed genes were predicted to be regulated by JA and/or ET signaling, confirming earlier findings that colonization of the roots by WCS417r primed Arabidopsis plants for augmented expression of the JA- and/or ET-responsive genes AtVSP2, PDF1.2 and HEL (Van Wees et al., 1999; Hase et al., 2003).

Priming is a phenomenon that is associated with different types of induced resistance (Conrath et al., 2002; Conrath et al., 2006). It provides the plant with an enhanced capacity for rapid and effective activation of cellular defense responses once a pathogen is contacted, and it allows the plant to react more effectively to any invader encountered by boosting the defenses that are activated in the host. This mechanism could also explain the broad-spectrum action of induced resistance. Priming for defense may combine advantages of enhanced disease protection with low metabolic costs. Recently, Van Hulten et al. (2006) examined the costs and benefits of priming in comparison to activated defense in Arabidopsis. The study 
revealed that the benefits of priming-mediated resistance outweigh the costs under conditions of pathogen pressure, suggesting an evolutionary advantage of this mechanism of induced resistance over constitutive activation of defense responses. Figure 1 provides a schematic representation of the ISR signaling pathway in Arabidopsis.

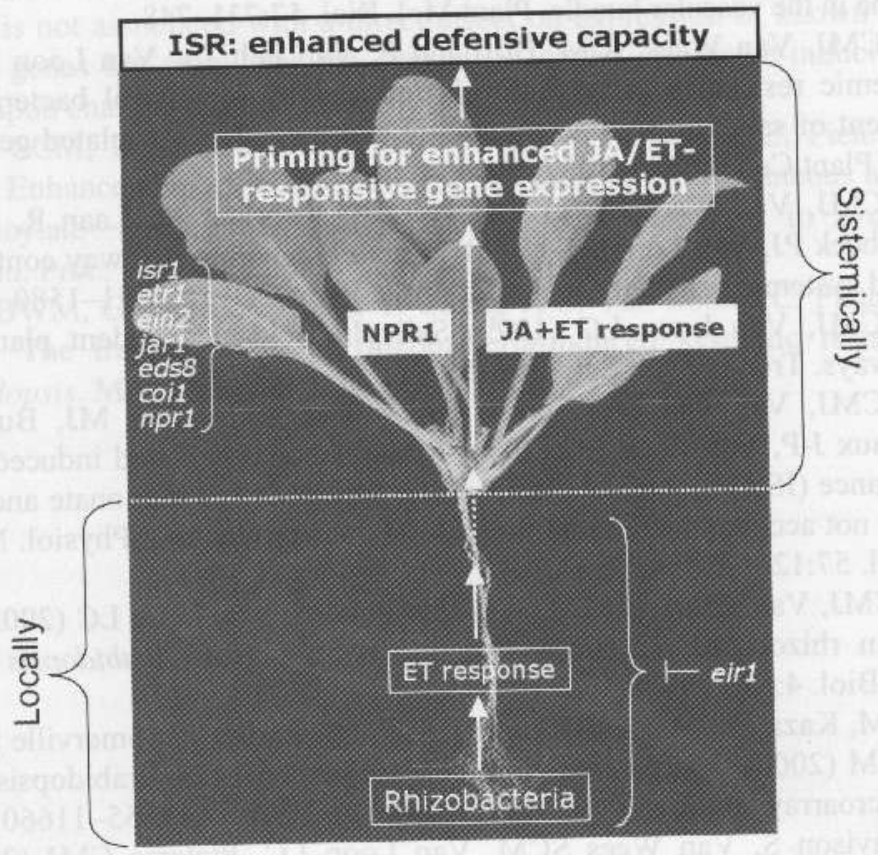

Fig. 1. Schematic representation of the Pseudomonas fluorescens WCS417rmediated ISR signaling pathway in Arabidopsis.

\section{References}

Conrath U, Pieterse CMJ, Mauch-Mani B (2002) Priming in plant-pathogen interactions. Trends Plant Sci. 7:210-216

Conrath U, Beckers GJM, Flors V, García-Agustín P, Jakab G, Mauch F, Newman M-A, Pieterse CMJ, Poinssot B, Pozo MJ, Pugin A, Schaffrath U, Ton J, Wendehenne W, Zimmerli L, Mauch-Mani B (2006) Priming: getting ready for battle. Mol. Plant-Microbe Interact. 19(10):1062-1071

Durrant WE, Dong X (2004) Systemic acquired resistance. Annu. Rev. Phytopathol. 42:185-209

Hase S, Van Pelt JA, Van Loon LC, Pieterse CMJ (2003) Colonization of Arabidopsis roots by Pseudomonas fluorescens primes the plant to produce higher levels of ethylene upon pathogen infection. Physiol. Mol. Plant Pathol. 62:219-226 
Knoester M, Pieterse CMJ, Bol JF, Van Loon LC (1999) Systemic resistance in Arabidopsis induced by rhizobacteria requires ethylene-dependent signaling at the site of application. Mol. Plant-Microbe Interact. 12:720-727

Léon-Kloosterziel KM, Verhagen BWM, Keurentjes JJB, Van Pelt JA, Rep M, Van Loon LC, Pieterse CMJ (2005) Colonization of the Arabidopsis rhizosphere by fluorescent $P$ seudomonas spp, activates a root-specific, ethylene-responsive $P R-$ 5 gene in the vascular bundle. Plant Mol. Biol. 57:731-748

Pieterse CMJ, Van Wees SCM, Hoffland E, Van Pelt JA, Van Loon LC (1996) Systemic resistance in Arabidopsis induced by biocontrol bacteria is independent of salicylic acid accumulation and pathogenesis-related gene expression. Plant Cell 8:1225-1237

Pieterse CMJ, Van Wees SCM, Van Pelt JA, Knoester M, Laan R, Gerrits H, Weisbeek PJ, Van Loon LC (1998) A novel signaling pathway controlling induced systemic resistance in Arabidopsis. Plant Cell 10:1571-1580

Pieterse CMJ, Van Loon LC (1999) Salicylic acid-independent plant defence pathways. Trends Plant Sci. 4:52-58

Pieterse CMJ, Van Pelt JA, Ton J, Parchmann S, Mueller MJ, Buchala AJ, Métraux J-P, Van Loon LC (2000) Rhizobacteria-mediated induced systemic resistance (ISR) in Arabidopsis requires sensitivity to jasmonate and ethylene but is not accompanied by an increase in their production. Physiol. Mol. Plant Pathol. 57:123-134

Pieterse CMJ, Van Wees SCM, Ton J, Van Pelt JA, Van Loon LC (2002) Signalling in rhizobacteria-induced systemic resistance in Arabidopsis thaliana. Plant Biol. 4:535-544

Schenk PM, Kazan K, Wilson I, Anderson JP, Richmond T, Somerville SC, Manners JM (2000) Coordinated plant defense responses in Arabidopsis revealed by microarray analysis. Proc. Natl. Acad. Sci. USA 97:11655-11660

Ton J, Davison S, Van Wees SCM, Van Loon LC, Pieterse CMJ (2001) The Arabidopsis ISRI locus controlling rhizobacteria-mediated induced systemic resistance is involved in ethylene signaling. Plant Physiol. 125:652-661

Ton J, Pieterse CMJ, Van Loon LC (1999) Identification of a locus in Arabidopsis controlling both the expression of rhizobacteria-mediated induced systemic resistance (ISR) and basal resistance against Pseudomonas syringae pv. tomato. Mol. Plant-Microbe Interact. 12:911-918

Ton J, De Vos M, Robben C, Buchala A, Métraux J-P, Van Loon LC, Pieterse CMJ (2002a) Characterization of Arabidopsis enhanced disease susceptibility mutants that are affected in systemically induced resistance. Plant J. 29:11-21

Ton J, Van Pelt JA, Van Loon LC, Pieterse CMJ (2002b) Differential effectiveness of salicylate-dependent and jasmonate/ethylene-dependent induced resistance in Arabidopsis. Mol. Plant-Microbe Interact. 15:27-34

Ton J, Van Pelt JA, Van Loon LC, Pieterse CMJ (2002c) The Arabidopsis ISRI locus is required for rhizobacteria-mediated induced systemic resistance against different pathogens. Plant Biol. 4:224-227

Van Hulten M, Pelser M, Van Loon LC, Pieterse CMJ, Ton J (2006) Costs and benefits of priming for defense in Arabidopsis. Proc. Natl. Acad. Sci. USA 103:5602-5607 
Van Loon LC, Bakker PAHM, Pieterse CMJ (1998) Systemic resistance induced by rhizosphere bacteria. Annu. Rev. Phytopathol. 36:453-483

Van Loon LC, Rep M, Pieterse CMJ (2006) Significance of inducible defenserelated proteins in infected plants. Annu. Rev. Phytopathol, 44:135-162

Van Wees SCM, Luijendijk M, Smoorenburg I, Van Loon LC, Pieterse CMJ (1999) Rhizobacteria-mediated induced systemic resistance (ISR) in Arabidopsis is not associated with a direct effect on expression of known defenserelated genes but stimulates the expression of the jasmonate-inducible gene Atvsp upon challenge. Plant Mol. Biol. 41:537-549

Van Wees SCM, De Swart EAM, Van Pelt JA, Van Loon LC, Pieterse CMJ (2000) Enhancement of induced disease resistance by simultaneous activation of salicylate- and jasmonate-dependent defense pathways in Arabidopsis thaliana. Proc. Natl. Acad. Sci. USA 97:8711-8716

Verhagen BWM, Glazebrook J, Zhu T, Chang H-S, Van Loon LC, Pieterse CMJ (2004) The transcriptome of rhizobacteria-induced systemic resistance in Arabidopsis. Mol. Plant-Microbe Interact. 17:895-908 


\section{A. Ramina · C. Chang J. Giovannoni · H. Klee P. Perata - E. Woltering Editors}

\section{Advances in Plant}

Ethylene Research

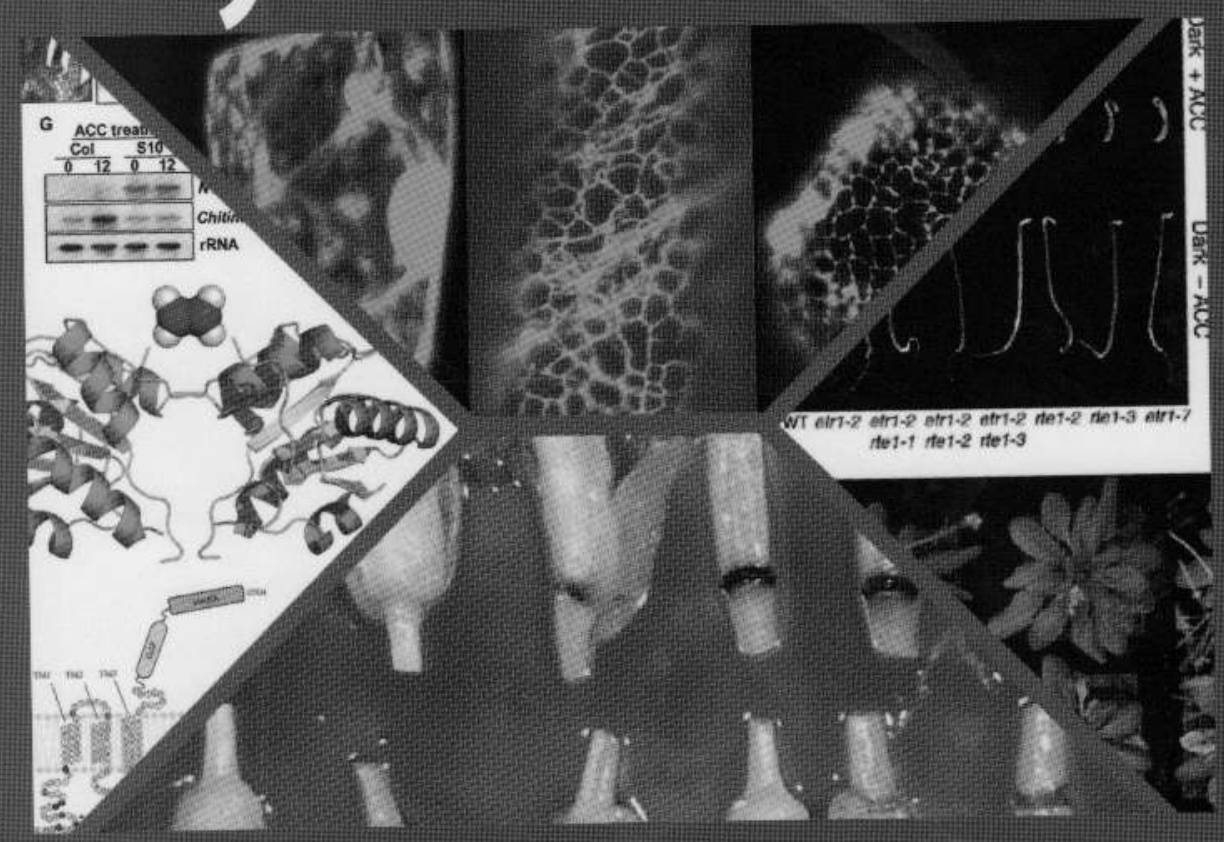

Q2) Springer 


\section{Advances in Plant Ethylene Research}

\section{Proceedings of the 7 th International Symposium on the Plant Hormone Ethylene}

Edited by

Angelo Ramina

University of Padova,

Department of Environmental Agronomy and Crop Science,

Legnaro (Padova), Italy

Caren Chang

University of Maryland,

Department of Cell Biology and Molecular Genetics,

Maryland, U.S.A.

Jim Giovannoni

Cornell University,

Boyce Thompson Institute for Plant Research,

Ithaca, U.S.A.

Harry Klee

University of Florida,

Horticultural Sciences,

Gainesville, U.S.A.

Pierdomenico Perata

Scuola Superiore Sant'Anna,

Pisa, Italy

and

Ernst Woltering

Wageningen University and Research Centre,

Agrotechnology and Food Sciences Group (AFSG),

Wageningen, The Netherlands 